\title{
Daya Dukung Habitat Terhadap Ketersediaan Pakan Gajah Sumatera Yang Ditangkarkan Di Kawasan Hutan Dengan Tujuan Khusus (KHDTK) Aek Nauli Provinsi Sumatera Utara
}

\author{
Carrying Capacity of Habitat Supports to Availabitity of Sumatran Elephant \\ Feed Captured in Forest Areas With Special Purpose Aek Nauli, \\ North Sumatra Province
}

\author{
Devi Kristina Br Ginting ${ }^{1}$, Saida Rasnovi ${ }^{1}$, Iqbar ${ }^{1}$ \\ 1Program Studi Kehutanan PSDKU Unsyiah Gayo Lues \\ Universitas Syiah Kuala \\ *Corresponding author: iqbar@unsyiah.ac.id
}

\begin{abstract}
Abstrak. Kawasan Hutan Dengan Tujuan Khusus (KHDTK Aek Nauli merupakan salah satu KHDTK yang ditetapkan melalui surat keputusan menteri kehutanan no. 39/Menhut-II/2005, tanggal 7 Februari 2005 dengan luasan 1900 ha. Untuk alokasi habitat gajah sumatera diberikan 100 ha terletak pada ekosistem hutan sekunder. Penelitian ini bertujuan untuk mengetahui jenis pakan gajah sumatera dan menghitung daya dukung habitat terhadap ketersediaan pakan gajah sumatera. Metode yang digunakan dalam penelitian ini adalah analisis vegetasi dan menghitung daya dukung habitat. Analisis vegetasi yaitu metode jalur dan garis berpetak (Kusmana 1997, 2006) sebanyak 5 petak contoh diletakkan pada garis transek yang panjangnya $50 \mathrm{~m}$. Jumlah transek untuk analisis vegetasi adalah 2 transek. Ukuran petak contoh untuk setiap strata pertumbuhan adalah semai $2 \mathrm{~m} \times 2 \mathrm{~m}$, pancang $5 \mathrm{~m} \times 5 \mathrm{~m}$, dan tiang $10 \mathrm{~m} \times 10 \mathrm{~m}$. Untuk menghitung daya dukung pakan gajah dilakukan dengan menentukan tumbuhan pakan gajah yang terdapat pada petak pengamatan lalu memilih bagian tumbuhan yang dimakan yang memiliki karateristik jumlah daun, panjang, dan diameter ranting yang relatif sama sebanyak 4-5 ranting contoh dalam satu individu, kemudian memotong contoh daun/ranting pertama untuk ditimbang $\mathrm{k}$, pemotongan kembali contoh daun/ranting kedua dan seterusnya dalam selang waktu 1 minggu dalam 4 minggu. Berdasarkan hasil perhitungan diketahui bahwa daya dukung habitat gajah sumatera di KHDTK Aek Nauli dengan luasan 100 ha dengan proper use 60\%, dan kebutuhan per ekor gajah rata-rata $250 \mathrm{~kg} /$ hari adalah 1,71 ha/ekor/hari.
\end{abstract}

Kata kunci. Gajah sumatera, daya dukung habitat di KHDTK Aek Nauli

Abstract. Forest Areas with Special Purposes (KHDTK Aek Nauli is one of the KHDTKs stipulated by the Minister of Forestry Decree No. 39 / Menhut-II / 2005, dated February 7, 2005 with an area of 1900 ha. For the allocation of habitat for Sumatran elephants given 100 ha located in the secondary forest ecosystem. This study aims to determine the type of food for Sumatran elephants and to calculate the carrying capacity of the habitat on the availability of food for Sumatran elephants. The method used in this research is vegetation analysis and to calculate the carrying capacity of the habitat (Kusmana 1997, 2006). As many as 5 sample plots were placed on the transect line with a length of 50 meters. A total of 5 sample plots were placed on the transect line whose length was $50 \mathrm{~m}$. The number of transects for vegetation analysis is 2 transects. The size of the sample plots for each growth stratum is $2 \mathrm{~m} \times 2 \mathrm{~m}$ seedlings , $5 \mathrm{~m} \times 5 \mathrm{~m}$ stakes, and $10 \mathrm{~m} \times 10 \mathrm{~m}$ piles. To calculate the feed bearing capacity $h$ is done by determining the elephant food plants found in the observation plot then selecting the part of the edible plant which has the characteristics of the number of leaves, length and diameter of the branches which are relatively the same as many as 4-5 sample twigs in one individual, then cutting the sample of the first leaf / twig to weighed k, cutting back the second sample of leaves / twigs and so on at intervals of 1 week in 4 weeks. Based on the calculation, it is known that the carrying capacity of the Sumatran elephant habitat in KHDTK Aek Nauli is 100 ha with $60 \%$ proper use, and the average requirement for each elephant is $250 \mathrm{~kg} /$ day is $1.71 \mathrm{ha} / \mathrm{individu/day}$. 
Keywords. Sumatran elephants, habitat support capacity in KHDTK Aek Nauli

\section{PENDAHULUAN}

Populasi gajah sumatera (Elephas maximus sumatranus) di alam jumlahnya semakin hari semakin mengalami penurunan yang cukup signifikan karena degradasi habitat. Kawasan Hutan Dengan Tujuan Khusus (KHDTK) Aek Nauliyang berfungsi sebagai daerah tangkapan air berada pada ketinggian 1.100-1.750 m dari permukaan laut memiliki tipe ekosistem hutan primer, hutan sekunder dan hutan tanaman, khususnya pinus. KHTDK Aek Nauli memiliki kemiringan lahan antara 3-65\% dengan dominasi kemiringan 0-5 mencapai $60 \%$ sehingga menjadi lokasi yang sesuai untuk pergerakan gajah sumatera (Susetyo, 1980). Ekosistem hutan sekunder dengan luas 100 ha dari total 1.900 ha KHDTK Aek Nauli diperuntukkan sebagai kawasan penangkaran gajah sumatera. Hal ini karena sifat dari gajah sumatera sebagai pemakan semak dan dedaunan yang mudah dipenuhi di kawasan hutan sekunder. Gajah pengakaran ini berasal dari gajah sumatera liar yang sering berkonflik dengan masyarakat ditangkap dan dijinakkan (captive) dan empat dari populasi tersebut kemudian ditempatkan di KHDTK Aek Nauli. KHDTK Aek Nauli dinilai dapat menjadi habitat bagi gajah sumatera hasil penjinakan tersebut.

Selain jenis ekosistem dan tingkat kelerengan lahan, syarat lainnya yang harus dipenuhi sebagai habitat yang dikategorikan sesuai untuk penangkaran gajah sumatera adalah tercukupinya kebutuhan pakan. Kebutuhan pakan gajah sumatera dalam sehari mencapai $250 \mathrm{~kg}$ atau setara dengan $10 \%$ dari bobot tubuhnya. Aktivitas makan gajah sumatera dalam sehari menghabiskan waktu $82,2 \%$ dari total aktivitas hariannya. Sisanya untuk aktivitas minum, berjalan, dan istrirahat (Sitompul, 2011). Preferensi jenis pakan yang tersedia sangat dipengaruhi oleh tingkat palatabilitas dari jenis pakan tersebut. Untuk menilai apakah KHDTK Aek Nauli menyediakan ketersediaan pakan yang cukup terhadap penangkaran empat gajah sumatera maka diperlukan penelitian daya dukung habitat terhadap ketersediaan pakan gajah yang ditangkarkan di lokasi tersebut.

\section{METODE PENELITIAN}

\section{Lokasi}

Lokasi penelitian dilakukan di Kawasan Hutan Dengan Tujuan Khusus (KHDTK) Aek Nauli Desa Sibaganding, Kecamatan Girsang Sipanganbolon, Kabupaten Simalungun, Provinsi Sumatera Utara.

\section{Alat dan Bahan}

Alat yang digunakan pada saat penelitian adalah kamera, alat tulis, tally sheet, timbangan, pita ukur (meter), dan patok kayu. Bahan yang digunakan adalah daftar tumbuhan pakan gajah sumatra yang sudah tersedia dari instansi KHDTK Aek Nauli

\section{Metode Penelitian}

Untuk mengetahui jenis tumbuhan yang ada di KHDTK Aek Nauli maka dilakukan analisis vegetasi. Analisis vegetasi pada penelitian ini menggunakan metode jalur yang 
dikombinasikan dengan garis berpetak (Kusmana, 1997). Jalur dibuat sebanyak 2 unit berbentuk transek/garis dengan panjang masing-masing $50 \mathrm{~m}$ dan dan jarak antar jalur juga $50 \mathrm{~m}$. Jalur dipilih secara sengaja (purposive sampling) pada wilayah hutan sekunder yang dijadikan sebagai kawasan peng-angonan gajah yang ditangkarkan tersebut. Pada setiap jalur ditempatkan/diletakkan 5 unit petak bersarang (Belt Transek) dengan ukuran $2 \mathrm{mx} 2 \mathrm{~m}$ untuk semai, 5mx5m untuk pancang, dan 10mx10m untuk tiang (Gambar 1). Strata pohon tidak dilakukan analisis vegetasi karena gajah penangkaran di wilayah ini tidak dapat memanfaatkan makanan dari pohon akibat susah mengapai sumber makanan tersebut.

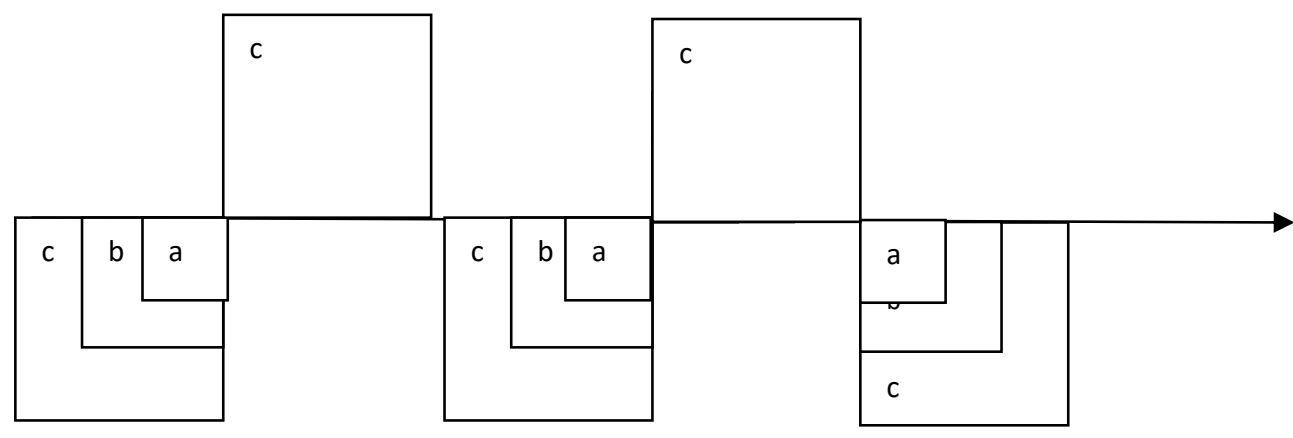

Gambar 1. Jalur transek dan Penempatan Petak Bersarang

Untuk menentukan produktivitas pakan dilakukan dengan cara menentukan tumbuhan pakan secara acak pada setiap strata pertumbuhan baik semai, pancang maupun tiang sebanyak 4 jenis berdasarkan data analisis vegetasi yang telah dilakukan. Selanjutnya memlilih bagian daun/ranting yang biasanya menjadi makanan gajah sumatera di KHDTK Aek Nauli dengan karakteristik jumlah daun, panjang, dan diameter ranting yang relatif sama, sebanyak 4-5 ranting contoh dalam satu individu dari 4 jenis tumbuhan yang telah dipilih. Daun/ranting contoh tersebut dipanen dengan cara dipotong setiap minggunya, kemudian ditimbang beratnya dan dicatat dalam tally sheet. Pemanenan daun/ranting terhadap jenis tanaman yang dipilih dilakukan setiap minggu hingga minggu ke 4 atau 5 sesuai dengan jumlah daun/ranting dari setiap strata pertumbuhan yang telah dipilih. Datadata ini selanjutnya digunakan untuk untuk menghitung daya dukung habitat KHDTK terhadap ketersediaan pakan gajah sumatera yang ditangkarkan di wilayah tersebut dengan menggunakan formula yang dikemukakan oleh Susetyo, 1980, seperti ditampilkan di bawah ini:

Daya Dukung $=\frac{\mathrm{A} \times \mathrm{B} \times \mathrm{C}}{\mathrm{D}}($ Satuan daya dukung habitat $=$ ha/ekor $)$

Keterangan:

$\mathrm{A}=$ produktivitas hijauan/ hari $(\mathrm{kg} / \mathrm{hari})$

$\mathrm{B}=$ proper use $(60 \%)$; berdasarkan kelerengan

$\mathrm{C}=$ luas permukaan yang ditumbuhi hijauan pakan gajah (ha)

$\mathrm{D}=$ kebutuhan pakan gajah/ ekor/ hari (kg/ekor/ hari) 
JURNAL ILMIAH MAHASISWA PERTANIAN

E-ISSN: 2614-6053 P-ISSN: 2615-2878

Volume 5, Nomor 4, November 2020 www.jim.unsyiah.ac.id/JFP 


\section{HASIL DAN PEMBAHASAN}

\section{Jenis Tumbuhan Pakan Gajah di KHDTK Aek Nauli}

Setelah dilakukan analisis vegetasi diketahui ada 14 jenis pakan gajah sumatera dari tiga strata yaitu semai, pancang dan tiang yang termasuk dalam 10 familia (Tabel 1) yang terdapat di Kawasan Penangkaran Gajah Sumatera KHDTK Aek Nauli . Untuk setiap tegakan pakan gajah yang teramati ditemukan tahap pertumbuhan tingkat semai sebanyak 14 jenis dan 10 familia, pada tingkat pancang sebanyak 6 jenis dan 6 familia, dan pada tingkat tiang sebanyak 3 jenis dan 3 familia. Yoza (2005) dan Djufri (2003) menyatakan bahwa tumbuhan dari suku poaceae merupakan tumbuhan yang disukai gajah, karena selain memiliki tekstur morfologi yang lunak, fisiknya berupa rerumputan, semak atau perdu sehingga gajah lebih mudah menjangkaunya dari pada dedaunan dari pohon tinggi.

Tabel 1. Jenis tumbuhan pakan gajah sumatera di KHDTK Aek Nauli

\begin{tabular}{rlll}
\hline No & Nama ilmiah & Family & Nama lokal \\
\hline 1 & Arenga pinnata Merr. & Arecaceae & Aren \\
2 & Calamus Sp. & Arecaceae & Rotan \\
3 & Macaranga triloba Muell.Arg. & Euphorbiaceae & Mahang damar \\
4 & Macaranga lowii King ex Hook.f. & Euphorbiaceae & Sitarak \\
5 & Quercus gemelliflora Blume. & Fagaceae & Hoting batu \\
6 & Calliandra calothyrsus Meisn. & Fabaceae & Kaliandra \\
7 & Litsea sumatrana Boerl. & Lauraceae & Medang Kertas \\
8 & Aglaia argentea Blume. & Meliaceae & Balik angin \\
9 & Eugenia fastigiata Miq. & Myrtaceae & Jambu-jambu \\
10 & Hierochloe odorata P.Beauv. & Poaceae & Rumput manis \\
11 & Imperata cylindrica Beauv. & Poaceae & Ilalang \\
12 & Ottochloa nodosa Kunth. & Poaceae & Rumput bambu \\
13 & Pandanus atrocarpus Griff. & Pandanceae & Pandan \\
14 & Mesophlebion chlamydophorum C.Chr. & Thelypteridaceae & Paku \\
\hline
\end{tabular}

\section{Daya Dukung Ketersediaan Pakan Gajah Sumatera}

Pengelolaan pakan gajah sumatera di KHDTK Aek Nauli meliputi pakan alami dan pakan tambahan. Penghitungan daya dukung habitat terhadap ketersediaan pakan gajah 
sematera di wilayah ini hanya untuk pakan alami yaitu tumbuhan yang ada di hutan sekunder dan dimakan langsung oleh gajah saat dilakukan pengangonan gajah tersebut. Ketersediaan (produktivitas) pakan gajah sumatera di Aek Nauli sesuai dengan tingkat tegakan ditampilkan pada tabel 2 .

Tabel 2. Produktivitas Pakan Alami Gajah Sumatera di KHDTK Aek Nauli

\begin{tabular}{|l|c|c|}
\hline Tingkat Pertumbuhan & $\begin{array}{c}\text { Produktivitas } \\
\text { kg/ha/hari }\end{array}$ & $\begin{array}{c}\text { Produktivitas } \\
\text { Kg/100 ha/hari }\end{array}$ \\
\hline Semai & 292,63 & 29263 \\
\hline Pancang & 0,80 & 80 \\
\hline Tiang & 0,02 & 2 \\
\hline Total & 293,45 & 29345 \\
\hline
\end{tabular}

Produktivitas tumbuhan pakan di KHDTK Aek Nauli menurut tingkat pertumbuhan sesuai dengan Tabel 3 di atas adalah pada tingkat semai adalah 292,63 kg/hari/ha, pancang $0,8 \mathrm{~kg} / \mathrm{hari} / \mathrm{ha}$, dan tiang $0,02 \mathrm{~kg} / \mathrm{hari} / \mathrm{ha}$. Total produktivitas tumbuhan pakan alami gajah dari semua tingkat pertumbuhan adalah sebanyak $293,45 \mathrm{~kg} / \mathrm{hari} / \mathrm{ha}$. Total luas area KHDTK Aek Nauli yang dapat digunakan oleh gajah sumatera adalah 100 ha yaitu pada kawasan hutan sekunder. Dengan demikian dapat dihitung produktivitas pakan yang tersedia di seluruh kawasan yang dapat digunakan oleh gajah sumatera yang ditangkarkan di KHDTK Aek Nauli pada masing-masing strata pertumbuhan adalah sebagaimana ditampilkan pada tabel 3. Tumbuhan tingkat pertumbuhan semai memiliki ketersediaan pakan alami sebanyak $29263 \mathrm{~kg} / 100 \mathrm{ha} / \mathrm{hari}$. Pakan pada strata ini merupakan pakan favorit gajah sumatera karena teksturnya yang lunak. Pakan alami gajah sumatera di KHDTK Aek Nauli pada tingkat pancang tersedia sebanyak $80 \mathrm{~kg} / 100 \mathrm{ha} / \mathrm{hari}$, dan pada tingkat tiang sebanyak $2 \mathrm{~kg} / 100$ ha/hari. Dengan demikian dalam waktu satu hari tersedia total produktivitas pakan alami gajah sumatera di KHDTK Aek Nauli adalah 29345 kg/100 ha/hari. Dalam kurun waktu satu tahun maka produktivitas hijauan pakan alami gajah sumatera di KHDTK Aek Nauli mencapai $10710925 \mathrm{~kg} / 100 \mathrm{ha} /$ tahun atau setara dengan 10,67 ton pakan alami/100 ha/tahun. Dalam pengelolaan habitat, daya dukung habitat umumnya didefinisikan sebagai jumlah populasi maximum suatu spesies tertentu yang dapat didukung kehidupannya secara tak-terbatas dalam suatu habitat tertentu tanpa menimbulkan gangguan keseimbangan produktivitas secara permanen dalam habitat bersangkutan (Priyono 2007). Berdasarkan hasil perhitungan yang diketahui bahwa daya dukung habitat gajah sumatera di KHDTK Aek Nauli dengan luasan 100 ha dengan proper use 60\%, dan kebutuhan per ekor gajah rata-rata $250 \mathrm{~kg} /$ hari menghasilkan 1,71 ha/ekor/hari.

Kebutuhan pakan gajah sumatera perekor/hari di KHDTK Aek Nauli adalah $250 \mathrm{~kg}$, sehingga dengan ada 4 ekor gajah yang ditangkarkan di sana maka kebutuhan pakannya adalah $1000 \mathrm{~kg}$ ( 1 ton) pakan/hari. Total persediaan makanan perhari di KHDTK Aek Nauli adalah $29345 \mathrm{~kg}$ pakan/hari. Dengan demikian KHDTK Aek Nauli mengalami surplus pakan gajah perhari adalah sebanyak 28,345 ton. Dengan demikian daya dukung habitat terhadap ketersediaan pakan gajah sumatera penangkaran di KHDTK Aek Nauli dalam kondisi sangat baik, bahkan mengalami surplus makan. 


\section{KESIMPULAN}

1. Terdapat 14 jenis pakan alami gajah sumatera dalam 10 petak pengamatan yaitu Arenga pinnata Merr. (aren), Calamus Sp. (rotan), Macaranga triloba Muell.Arg. (mahang damar), Macaranga lowii King ex Hook.f (sitarak), Quercus gemelliflora Blume (hoting batu), Calliandra calothyrsus Meisn. (kaliandra), Litsea sumatrana Boerl. (medang kertas), Aglaia argentea Blume. (balik angin), Eugenia fastigiata Miq. (jambu-jambu), Hierochloe odorata P.Beauv (rumput manis), Imperata cylindrica Beauv. (ilalang), Ottochloa nodosa Kunth. (rumput bambu), Pandanus atrocarpus Griff. (pandan), Mesophlebion chlamydophorum C.Chr. (paku).

2. Data dukung habitat gajah sumatera di KHDTK Aek Nauli 1,71 ha/ekor/hari dengan produktivitas 293,45 kg/hari/ha. 
JURNAL ILMIAH MAHASISWA PERTANIAN

E-ISSN: 2614-6053 P-ISSN: 2615-2878

Volume 5, Nomor 4, November 2020 www.jim.unsyiah.ac.id/JFP 


\section{DAFTAR PUSTAKA}

Kusmana, C.1997. Ekologi Dan Sumberdaya Ekosistem Mangrove. Bogor. Jurusan Manajemen Hutan Fakultas Kehutanan IPB.

Priyono, A. 2007. Pendekatan Ekologi dan Ekonomi dalam Penataan Kawasan Buru Rusa Sambar: studi Kasus Taman Buru Gunung Masigit-Kareumbi. Sisertasi. Sekolah Pascasarjana Institut Pertanian Bogor. Tidak diterbitkan.

Saleh, C dan Andriani. 2005. Petualangan Ghazu, Gajah Sumatera. Internal Report. WWF Indonesia. Jakarta.

Sitompul, A.F. 2011. Ecology and Conservation of Sumatran Elephants (Elephas maximus sumatranus) in Sumatra, Indonesia. Ph.D thesis. University of Massachusetts, Amherst, USA.

Susetyo, S. 1980. Padang pengembalaan. Bogor: Fakultas Peternakan, Institut Pertanian Bogor.

Yoza, D., 2005. Kajian Kurikulum Latihan Gajah di Pusat Konservasi Gajah Tahura Sultan Syarif Hasyim Riau. Laporan Penelitian. Universitas Riau. 